\title{
EDUKASI DAMPAK NEGATIF NAPZA PADA REMAJA DAN SOSIALISASI KESEHATAN JIWA MASYARAKAT PADA KADER DI DESA TAMBUNAN
}

\author{
Wardiyah Daulay $^{*}$, Sri Eka Wahyuni ${ }^{2}$, Mahnum Lailan ${ }^{3}$, Jenny M Purba \\ Universitas Sumatera Utara ${ }^{1,2,3,4}$ \\ wardiyah.daulay@usu.ac.id, eka_rizky06@yahoo.co.id, mahnum_lailan@yahoo.co.id
}

\begin{abstract}
ABSTRAK
Masalah penyalahgunaan narkotika, psikotropika dan zat adiktif lainnya (NAPZA) atau istilah yang dikenal masyarakat sebagai Narkoba (narkotika dan bahan/obat berbahaya) merupakan masalah yang sangat kompleks yang memerlukan upaya penanggulangan secara komprehensif multidisipliner, multi sektor dan peran serta masyarakat secara aktif yang dilaksanakan secara berkesinambungan, konsekuen dan konsisten. Tingkat pemakaian Napza di masyarakat Kabupaten Langkat yang meningkat, mengharuskan pemerintahan dan dinas kesehatan melakukan antisipasi untuk menekan jumlah pengguna dan penyalahgunaan Napza dimana dampak dari penyalahgunaan tersebut dapat mengakibatkan gangguan kejiwaan. Dari masalah ini dirancang suatu pemecahan masalah yakni melakukan penyuluhan kepada sekolah-sekolah yang beresiko dan penyegaran kader kesehatan terkait kesehatan jiwa di masyarakat.
\end{abstract}

Kata Kunci: NAPZA; Kesehatan Jiwa; Masyarakat

\begin{abstract}
The problem of the abuse of narcotics, psychotropic substances and other addictive substances (NAPZA) or a term known to the public as Narcotics (narcotics and dangerous substances / drugs) is a very complex problem that requires comprehensive multidisciplinary, multi-sector, and active community participation. on an ongoing basis, consequently and consistently. The increasing level of drug use in the Langkat Regency community requires the government and health offices to anticipate to reduce the number of drug users and abuse where the impact of this abuse can lead to mental disorders. From this problem, a solution to the problem was designed, namely providing counseling to schools at risk and refreshing health cadres related to mental health in the community.
\end{abstract}

Keywords: NAPZA; Mental Health; Public

\section{PENDAHULUAN}

Masalah penyalahgunaan narkotika, psikotropika dan zat adiktif lainnya (NAPZA) atau istilah yang dikenal masyarakat sebagai Narkoba (narkotika dan bahan/obat berbahaya) merupakan masalah yang sangat kompleks yang memerlukan upaya penanggulangan secara komprehensif multidisipliner, multi sektor dan peran serta masyarakat secara aktif yang dilaksanakan secara berkesinambungan, konsekuen dan konsisten. Banyaknya penyalahgunaan NAPZA tidak hanya di kota - kota besar saja, tetapi sudah sampai ke kota- kota kecil di seluruh wilayah republik Indonesia. Kecenderungannya semakin banyak masyarakat yang memakai NAPZA khususnya anak remaja (15-24 tahun) dimana remaja merupakan sasaran utama dalam perdagangan gelap NAPZA. 
Sektor kesehatan memegang peranan penting dalam upaya penanggulangan penyalahgunaan NAPZA. Peran penting sektor kesehatan sering tidak disadari oleh petugas kesehatan itu sendiri, bahkan para pengambil keputusan, kecuali mereka yang berminat di bidang jiwa, khususnya penyalahgunaan NAPZA. Bidang ini perlu dikembangkan secara professional, sehingga menjadi suatu pilar yang kokoh dari upaya penanggulangan penyalahgunaan NAPZA dimana puskesmas merupakan pelayanan kesehatan yang berperan lebih pro aktif dalam upaya penanggulangan NAPZA di masyarakat.

Berdasarkan survey yang dilakukan tim Fakultas Keperawatan di Desa Tambunan Kabupaten Langkat, didapat data bahwa banyak anak remaja yang sudah mengenal dan mengkonsumsi Napza. Dan menurut keterangan yang didapat dari tokoh masyarakat setempat, masyarakat jarang mendapat penyuluhan terutama tentang remaja dan kesehatan remaja. Khusus untuk penyuluhan tentang Napza masih jarang di lakukan di sekolah. Kemudian dari data Dinas Kesehatan didapat bahwa jumlah kader yang ada di desa tersebut berjumlah 80 orang, tetapi sangat jarang sekali dilakukan pertemuan-pertemuan ilmiah antar kader. Kader yang ada diberdayagunakan hanya untuk kesehatan fisik secara umum, sedangkan yang terkait dengan kesehatan jiwa belum tersentuh sama sekali. sehingga perlu dilakukan sosilisasi terkait kesehatan jiwa pada masyarakat.

Prevalensi remaja yang sudah mengenal dan mengkonsumsi Napza meningkat, termasuk remaja yang ada di Desa Tambunan Kabupaten Langkat. Sedangkan remaja banyak yang belum mengerti efek dari penggunaan Napza tersebut. Masyarakat Desa Tambunan juga tidak terpapar dengan informasi terkait kesehatan jiwa, termasuk kader yang ada di wilayah Desa Tambunan tersebut.

Adapun tujuan pengabdian adalah untuk menambah pengetahuan remaja tentang penyalahgunaan NAPZA dan untuk menambah informasi pada kader masyarakat di Desa Tambunan Kabupaten Langkat.

\section{PELAKSAAAN DAN METODE}

Data yang telah didapatkan dari tim survey dijadikan acuan dalam melaksanakan kegiatan. Kegiatan dilakukan dalam bentuk penyuluhan baik untuk penyuluhan Napza maupun sosialisasi kesehatan jiwa masyarakat pada kader, dan melakukan pre dan post sebagai evaluasi kegiatan penyuluhan. Evaluasi objektif dilakukan dengan tanya jawab dan diskusi terkait materi yang disampaikan pada penyuluhan. Untuk evaluasi subjektif dilakukan ekspress feeling setelah berakhirnya kegiatan pengabdian.

\section{HASIL DAN PEMBAHASAN}

\section{Hasil Pelaksanaan Penyuluhan Napza}

Pelaksanaan dilakukan dengan beberapa susunan acara yang dihadiri oleh kepala sekolah, wakil kepala sekolah, guru-guru dari dua sekolah terkait, pengawas sekolah dan tim dari Puskesmas. Setelah kata sambutan dari kepala sekolah, acara kemudian dilanjutkan dengan penyuluhan tentang Napza. Sebelum dilakukan penyuluhan, terlebih dahulu dilakukan pengukuran awal (pre test) untuk mengetahui tingkat pengetahuan siswa tentang Napza. Pengukuran awal tersebut dilakukan dengan memberikan siswa 5 buah pertanyaan terkait Napza. Dan berdasarkan hasil pretest didapat data bahwa rata-rata tingkat pengetahuan siswa adalah 4,08. 
Pelaksanaan penyuluhan berlangsung selama 2 jam, yang terdiri dari 2 sesi, sesi pertama berupa pemaparan materi dari penyuluh dan sesi kedua tanya jawab tentang materi yang disampaikan. Materi yang disampaikan selama penyuluhan membahas tentang defenisi Napza, Jenis-Jenis Napza, Faktor- Faktor Penyalahgunaan Napza, Dampak Penyalahgunaan Napza dan Penanggulangan Penyalahgunaan Napza. Pada sesi kedua antusias siswa untuk bertanya sangat tinggi, terbukti dari banyaknya siswa yang bertanya. Salah satu pertanyaan yang menarik adalah apa hubungan pergaulan bebas dengan penyalahgunaan Napza.

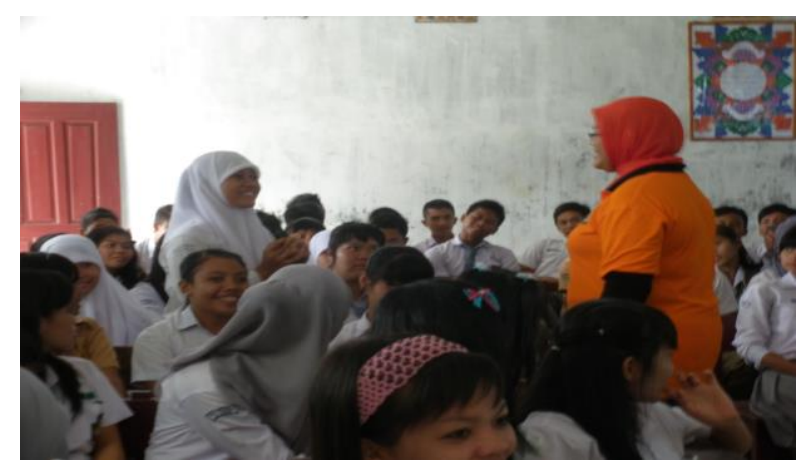

Gambar 1. Kegiatan diskusi pada Edukasi Dampak Napza

Sebelum penyuluhan ditutup dilakukan lagi pengukuran pengetahuan (post test) untuk mengukur tingkat pengetahuan siswa setelah materi disampaikan. Setelah dilakukan pengolahan data, didapat bahwa tingkat pengetahuan siswa terkait Napza meningkat secara signifikan yaitu menjadi 5,85. Artinya terjadi peningkatan pengetahuan siswa dari 4,08 menjadi 5,85.

Tabel 1. Rata-Rata Pengetahuan Siswa tentang Napza

\begin{tabular}{lcc}
\hline \multicolumn{1}{c}{ Kategori } & Rata-rata & Selisih \\
\hline Pre test & 4,08 & 1,77 \\
Post test & 5,85 & \\
\hline
\end{tabular}

Di akhir acara, tim penyuluh melakukan ekspress feeling terhadap siswa dan memberikan reward kepada tiga siswa yang memiliki nilai tertinggi berupa alat tulis. Kepada seluruh siswa diberikan leaflet Napza dan untuk sekolah diberikan poster dalam bentuk x-banner.

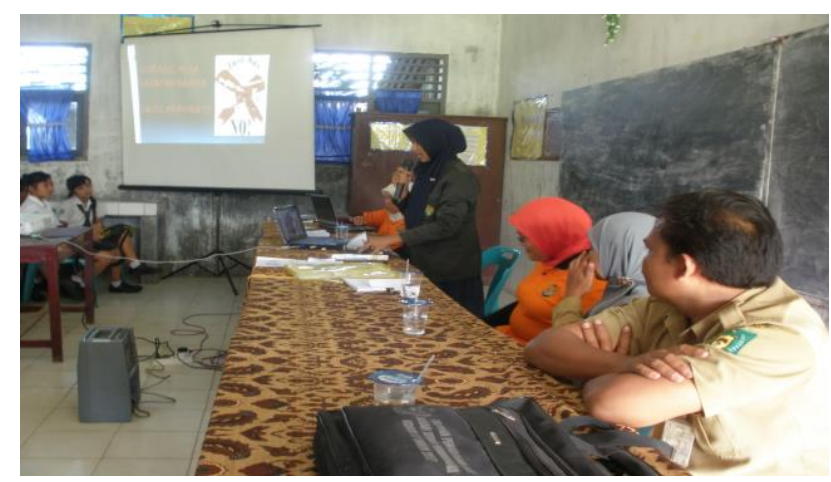

Gambar 2. Kegiatan ekspres feeling 


\section{Hasil Pelaksanaan Sosialisasi Kesehatan Jiwa Masyarakat}

Pelaksanaan sosialisasi kesehatan jiwa masyarakat pada kader dilakukan sekitar 1 jam. Pelaksanaannya sendiri dilakukan setelah acara seremonial yang dilakukan di Puskesmas yang dihadiri oleh kepala dinas kesehatan yang mewakili Bupati Langkat, 3 orang kepala puskesmas (Salapian, Tanjung langkat dan Marike), ketua PPNI langkat. Acara di buka langsung oleh kepala dinas kesehatan. Selanjutnya materi tentang kesehatan jiwa diberikan kepada para kader dan materi yang disampaikan mendapat respon yang sangat baik dari para peserta ditandai banyaknya pertanyaan yang diajukan oleh para kader.

Waktu yang dibutuhkan untuk sosialisasi kesehatan jiwa selama 1 jam dimana materi yang disampaikan adalah defenisi kesehtan jiwa, cirri- cirri sehat jiwa, masalah masalah psikososial beserta tanda -tanda yang dapat diamati dan gangguan jiwa yang terjadi yang dapat muncul didalam masyarakat ditambah bagaimana penangangan yang dapat dilakukan masyarakat melalui kader kesehatan yang ada pada tingkat pecegahan primer, sekunder, tersier untuk mengoptimalkan pelayanan secara komprehensif. Sebelum berakhir sosialisasi diadakan evaluasi berupa pertanyaan yang diberikan kepada kader sebanyak 3 pertanyaan. Kader yang berani dan menjawab dengan benar langsung diberikan bingkisan untuk meningkatkan motivasi kader dalam mempelajari kesehatan jiwa masyarakat.

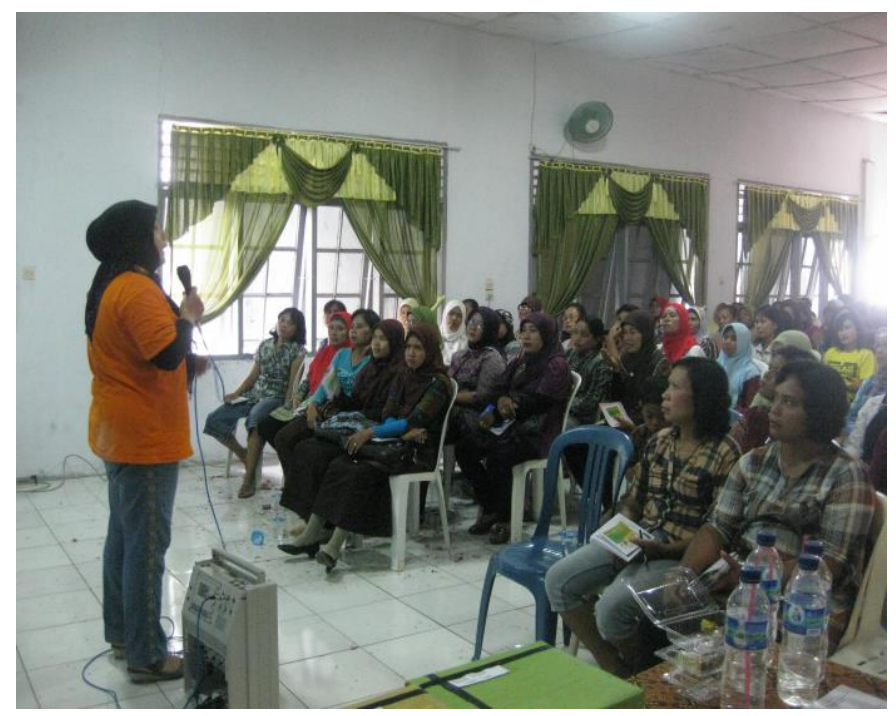

Gambar 3. Kegiatan sosialisasi kesehatan jiwa pada kader

Pada akhir sosialisasi, kader diberikan leaflet yang bisa dibawa pulang dan kemudian kader mengungkapkan perasaannya tentang kegiatan yang sudah dilakukan. Dan dari ekspress feeling tersebut banyak kader yang mengatakan sangat tertarik dalam mempelajari kesehatan jiwa di masyarakat. Karena topik ini merupakan sesuatu yang baru bagi para kader dan mengharapkan agar kegiatan seperti ini dilakukan secara berkesinambungan. 


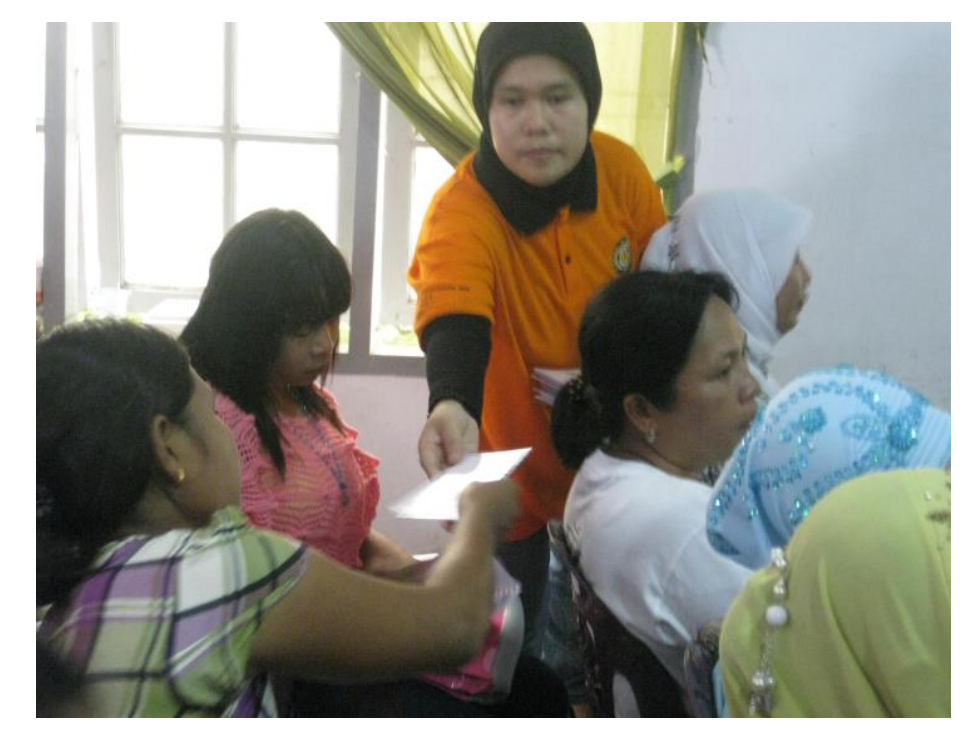

Gambar 4. Pembagian leaflet kesehatan jiwa masyarakat pada kader

\section{PEMBAHASAN}

Dari data didapatkan hasil bahwa terjadi peningkatan pengetahuan siswa terkait Napza sebelum dan sesudah dilakukan penyuluhan. Masalah penyalahgunaan Napza merupakan masalah yang sangat kompleks yang memerlukan upaya penanggulangan dengan melibatkan multidisiplin. Artinya masalah Napza tidak hanya menjadi tanggungjawab bagi pemerintah tetapi juga sector kesehatan. Salah satu upaya yang dapat dilakukan untuk penanggulangannya adalah dengan melakukan penyuluhan-penyuluhan pada remaja yang beresiko, seperti yang telah dilakukan di SMA Salapian.

Pengetahuan yang didapat dari penyuluhan diharapkan dapat menjadi dasar bagi siswa untuk menjauhi atau berhubungan dengan Napza. Banyaknya penyalahgunaan NAPZA disebabkan banyak faktor, yakni faktor individu, faktor keluarga dan faktor lingkungan .

Pencegahan penyalahgunaan napza merupakan persoalan yang komplek yang masih perlu banyak dipelajari tentang apa yang terbaik dilakukan dan oleh siapa, tenaga kesehatan tentunya memiliki peran yang sangat besar, namun program yang ada belum mencukupi untuk pencegahan secara efektif. Penyebab banyaknya pemakaian zat tersebut disebabkan karena faktor individu, faktor keluarga dan faktor lingkungan. Faktor individu kebanyakan dimulai pada saat remaja, sebab pada remaja sedang mengalami perubahan biologi, psikologi maupun sosial yang pesat dimana terdapat ciri - ciri remaja yang mempunyai resiko lebih besar menggunakan NAPZA yaitu cenderung memberontak, memiliki gangguan jiwa lain,misalnya : depresi, cemas, perilaku yang menyimpang dari aturan atau norma yang ada, kurang percaya diri, mudah kecewa, agresif ,murung, pemalu, pendiam, merasa bosan dan jenuh, keinginan untuk bersenang - senang yang berlebihan, kemampuan komunikasi yang rendah dan putus sekolah.

Faktor keluarga yaitu komunikasi orang tua dan anak kurang baik, hubungan kurang harmonis, orang tua yang bercerai/ kawin lagi, orang tua terlampau sibuk, acuh, otoriter, kurangnya orang yang menjadi teladan dalam hidup anak dan kurangnya kehidupan beragama di dalam suatu keluarga. sedangkan faktor lingkungan yaitu 
lingkungan sekolah yang kurang memberi kesempatan pada siswa untuk mengembangkan diri secara kreatif dan positif serta adanya murid yang menggunakan NAPZA, berteman dengan penyalahguna, dan situasi politik, sosial dan ekonomi yang kurang mendukung.

Dampak yang terjadi dari faktor-faktor di atas adalah individu mulai melakukan penyalahgunaan dan ketergantungan akan zat. Hal ini ditunjukkan dengan semakin banyaknya individu yang melakukan perampokan , pencurian, judi, tawuran , mabukmabukan, memperkosa dan sebagainya akibat dari penyalahgunaan dan ketergantungan zat yaitu mengalami intoksikasi zat dan withdrawal .

\section{PENUTUP}

\section{Kesimpulan}

Penyuluhan yang dilakukan pada anak SMA berdampak positif (signifikan) terhadap tingkat pengetahuan siswa terkait Napza. Dan sosialisasi kesehatan jiwa masyarakat pada kader sangat berdampak terhadap motivasi kader melakukan deteksi terhadap masyarakat yang beresiko.

\section{Saran}

Untuk Sekolah melakukan pengontrolan terhadap siswa secara kontiniu. Seluruh siswa diharapkan juga melakukan pengontrolan terhadap teman masing-masing dan melaporkan jika ada yang dicurigai.

Untuk Dinas Kesehatan membuat program-program untuk meminimalkan penyalahgunaan Napza seperti melakukan penyuluhan dan pendekatan berkesinambungan terhadap masyarakat dengan memberdayakan kader-kader yang sudah ada.

Untuk Pendidikan Keperawatan melakukan penyuluhan-penyuluhan berkesinambungan terhadap masalah-masalah kesehatan jiwa yang dapat diaplikasikan pada saat melakukan praktek profesi di komunitas.

\section{DAFTAR PUSTAKA}

Dalami, Ermawati. (2009). Asuhan Keperawatan Klien dengan Gangguan Jiwa. Jakarta : CV.Trans Info Media

Depkes. (2002). Keputusan Menteri kesehatan RI tentang pedoman penyelenggaraan sarana pelayanan rehabilitasi penyalahgunaan dan ketergantungan narkotika, psikotropika dan zat adiktif lainnya (NAPZA). Jakarta: Departemen Kesehatan RI..

Keliat, B.A, Panjaitan, R.U., \& Helena, N. (2006). Proses Keperawatan Jiwa Kesehatan Jiwa, Edisi 2. Jakarta: EGC

Purba, Jenny. M. (2008). Asuhan Keperawatan Pada Klien dengan Masalah Psikososial dan Gangguan Jiwa. Medan: USU Press

Juwana, Satya. (2005). Gangguan Mental dan Perilaku Akibat Penggunaan Zat Psikoaktif : Penyalahgunaan NAPZA/ Narkoba. Jakarta: EGC 